\title{
Interference in and Ecological Strategies to Mobile Financial Services Developed by Commercial Banks
}

\author{
Lingbo Xv, Qingjun Meng \\ Hehai University, Jiangning Campus, Nanjing City, China \\ Email: $\underline{\text { mjq@hhu.edu.cn }}$
}

Received 15 June 2015; accepted 7 July 2015; published 14 July 2015

\begin{abstract}
Internet-based mobile finance developed by commercial banks makes for the innovations of finance operation modes, and, as a result, can sharpen the competitive edge of the banks in the new normal economy. On the way to the development of mobile financial services, commercial banks may come up against roadblocks such as imperfect laws and regulations, intensive horizontal competition and shortage of talent, etc. In this regard, supportive national policies are crucial to the development of mobile finance. Only by enhancing financial innovations, attaching importance to talent and market analysis and collaborating with other organizations can the banks suppress the interference and build a mobile finance ecosphere suitable for their own development. In this study, the diamond model is used to analyze problems with qualitative analysis.
\end{abstract}

\section{Keywords}

Commercial Bank, Mobile Finance, Core Competitiveness, Diamond Model, Mobile Finance Ecosphere

\section{Introduction}

The rise of mobile internet in new economic environment brings both opportunities and challenges for the sustainable development of commercial banks. Internet-based mobile financial services developed by commercial banks can create new points of profit growth, make for new business modes, and improve competitiveness as well. Mobile internet finance, or mobile finance for short, is a new field that combines traditional finance with mobile internet. A variety of mobile internet tools, such as smartphone, tablet computer and wireless POS, etc., make traditional finance more transparent, participative and collaborative, with lower intermediate cost and easier operation. It breaks through the time-and-space restriction of PC-based internet and traditional finance. In addition, it is efficient in improving the finance services' coverage, availability and convenience, which allows people to take such services whenever and wherever they need. It therefore becomes an important platform to accelerate the development of both personal and inclusive finances.

Commercial banks, as the core of traditional financial sector in China, have advantages in risk control and as- 
set allocation. They hold a dominant position in developing mobile financial services, which, by far, have been provided by over 20 banks. For financial services, the dependence upon outlets can also be reduced by the internet. Many commercial banks are now attracted to the mobile finance industry for they have seen the great market demand due to the simplified process and lower cost. With the mobile communication terminals in the era of $4 \mathrm{G}$, internet players have found new ways in fierce competition. However, there are also a lot of interferences on the way of deepening financial transformation. For commercial banks under such profoundly changing economic behavior mode, how to eliminate interference of the internet industry, promote the development of mobile finance by advantage of the internet, enhance their core competitiveness and hold their market position has now become important issue concerned by both financial and academic circles.

\section{Relevant Studies}

As it becomes more possible that traditional PC-based internet may be replaced by the mobile one, mobile finance, including mobile payment and cellphone banking, is now a key direction for the development of the internet-based finance, and also an important field concerned by both financial and academic circles. As pointed by Xie Ping, financial business can be interpreted as mobile data, which will bring a revolutionary influence upon the finance mode. Besides, the spread of cellphone network is much faster than that of the PC network. As a result, the marker of the third party payment that determines the future developmental potential of internet finance is becoming more mobile. The mobile payment mode, including Alipay, Tenpay and QR code, is attracting more and more attention [1].

$\mathrm{Li}$ (2014) considers that mobile finance is an important direction for financial innovations, a major content for improving financial support, and also a significant platform for the development of inclusive finance. Acceleration of mobile finance can broaden the channel for financial services, improve financial products, speed up the pace of financial innovations and infuse new blood for both mode and structure transformations [2].

Cao (2014) points out that internet finance brings not only challenges and pressures to traditional banking business, but also opportunities for reformation and innovation, and requires traditional banking business to keep up with the pace of the era. What's more, traditional banking business has its own advantages, including its outlets and strengths built in the past. It is fair to say that progress can only be made by combining the internet and mobile platforms with traditional finance. In this regard, the internet-based finance shall be sincerely cooperated with the traditional one to design, jointly, new products [3].

$\mathrm{Hu}$ (2014) comes to a conclusion that, in future, mobile finance will be the main battlefield for the finance industry. To achieve a better development of internet banking business is to seize opportunities as well as to understand its essence and how it develops. Innovations in business mode, operation mode and management mode shall be made in the light of the internet, to establish the internet-based financial ecology [4].

As stated in Mobile Financial Services: State of the Industry Report by GSMA, a demonstration of the development trend of mobile finance, the number of active users of the mobile finance grows rapidly that it reaches to 61 million by June 2013, which was 37 million a year ago. The number of the mobile financial accounts by June 2013 is 203 millions, which is nearly three times of 71 millions created by June 2011. Meanwhile, an increasing number of suppliers are overcoming challenges to set up stable distribution networks as well as to find more active users. In turn, the increasing number of users of the mobile finance plays an important role in promoting the financial inclusion in developing countries [5].

The important functions of mobile finance as well as pressures on banks have been detailed in the above section. However, further and deep analysis shall still be made to figure out how to develop the internet-based mobile financial services, exploit its competitive advantages, remove interference and find out specific countermeasures.

\section{Research Methods and Cases}

\subsection{Research Methods}

Using the theory of competitive advantage, proposed by Michael E.Porter, together with the developmental characteristics of mobile financial services and the state of commercial banks, factors of the core competitiveness that have influence on commercial banks' mobile financial services are classified into seven elements. Based on Porter's "dynamic dual-diamond model", a qualitative analysis is carried out with taking into consideration of 
the interaction between technology, which is the core element, and other elements [6].

\subsection{Case Analysis}

\subsubsection{Mobile Financial Services by Shanghai Pudong Development Bank}

Actions taken by Shanghai Pudong Development Bank (SPD Bank for short) to develop mobile finance and to create "a leading bank of mobile finance" include (SPD Bank, 2014) [7]:

1) Build up the "three-three-five" strategy for mobile finance which includes three service ideas: personalization, scenarization and socialization; three dimensions: leading concept as the guide, leading technology as the support and leading market as the goal; and five mobilities: mobile payment, mobile bank, mobile life, mobile community and mobile marketing.

2) The Report on Development Tendency of Mobile Finance Industry and New Users, Jointly issued by SPD Bank, CMCC (China Mobile Communication Corporation) and Fudan University, issued the 3.0 standard of mobile finance, and pointed out that the era of the 3.0 standard-dominated "mobile finance ecosphere" is coming, which allows users to directly participate in financial production (Sheng, 2014) [8].

3) The direct banking system constructed by SPD Bank has achieved the application of all free electronic channels. Up to the release of the report, the number of users of cellphone banking reaches to 6.64 millions, and the transactions and the amount of money dealt by cellphone banking are 4 and 5.5 times more than those in 2013, respectively, with over $85 \%$ of the transactions being replaced by electronic channels.

4) On April 1, 2015, SPD Bank is the first to release the 7.0 version of cellphone bank, which puts emphasis on user experience. This totally new version, with taking into consideration of the habit of internet users, to "offer users with opening services as the role of an E-commerce player".

5) Armed all the financial managers of the Bank with the PAD mobile marketing platform.

\subsubsection{Dynamic Dual-Diamond Model}

Mobile finance is promoted mainly by technologies such as mobile communication and cloud computing. The macro-control effect by governmental policies also plays an important role in such promotion. There are seven elements, including technology which is the core, and the other key elements: production, demand conditions, related supportive industries, business strategy, structure and competitor, government, and the auxiliary element: opportunity, as shown in Figure 1.

1) As the development of the target market is mainly promoted by new technologies, the weight of the element of production is therefore changed, which reduces the impacts of basic production factors. Here our focus is on high-level elements of production, such as the processing of big data, the increasing of talents, and the investment in the target market by commercial banks. For their obvious capital advantages, commercial banks are able to make technological investment to boost the development of mobile financial services.

The quick upgrading of technologies requires commercial banks to attach importance to technical researches, increase investment in the target market, attract more high-level technical personnel, and hold their competitive positions. By now, the human resource of these banks is mainly structured by financial talents, who have limited

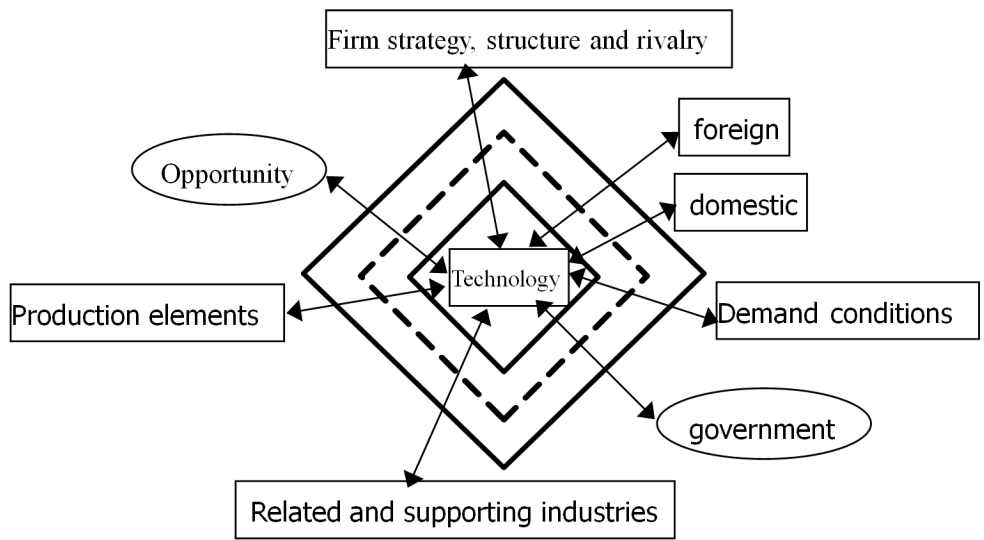

Figure 1. Dynamic double diamond model. 
knowledge about technologies of the mobile internet. The lack of technical personnel will bring interference when they develop mobile finance.

2) Demand conditions and technology

Demand determines production. Changes of the demand conditions in the target market have direct impact on the development of technologies. The increasing of GDP and PGDP ignites people's passion on finance, which is a favorable condition for the development of mobile finance. The group who have demand on mobile internet finance mainly are young people aged from 15 to 35 . This large group is in great demand. For another, the demand is also simulated, indirectly, by the interaction between demand and supply as well as by the popularization of mobile financial services. It can be seen that mobile financial services have a huge market. Commercial banks shall make full use of this advantage and shall expand the market by innovations.

New market demands also have new requirements on technologies. The platforms of mobile internet and technologies for processing information shall be simplified to raise the speed, so as to make respond to the "less, short-term, urgent and frequent" demands. Meanwhile, customer demands trend to be diversified, which are all required to be solved by the platform of mobile finance. For a traditional bank, a customer must make personal appearance in the bank to go through the long process for his/her banking affairs. This is opposite to the above demands, and thus brings interference to the development of commercial banks' mobile financial services.

3) Related supportive industries and technology

An explosive growth in the industry of mobile internet can be seen in recent years. Smartphones, as the major terminal of mobile internet, have entered into a mature period. The popularization of cheap smartphones make them become the main medium for mobile finance. The good mobile internet environment is also supported by the fast development of the mobile communication industry as well as by the construction of the $4 \mathrm{G}$ network. The internet industry, as a competitor of banks, also plays a role in promoting the strategic transformation of these banks.

Internet players such as Alibaba, driven by the increasingly intense horizontal competition, are stepping into the finance field, which is in favor of the utilization of mobile technologies. Depending on their strengths in internet platforms, these companies have now become powerful competitors of commercial banks. If commercial banks want to take a dominant position in competition, they must rely on technological innovations, make full use of big data and cloud computing to upgrade their mobile finance platforms, and the innovations shall also be made in procedure, business and channels.

4) Business strategy, enterprise structure, horizontal competition and technology

Mobile finance is a newly rising and high-tech industry that cores at technology. Commercial banks shall adjust their strategy, emphasize technological innovations, promote business transformation, and, strategically, underline the development of mobile finance. These shall be fully supported and implemented by senior managers. For this purpose, they shall make adjustment to their structure, set up the department of mobile finance, focus on the development of mobile financial services, set goals, and attract more talents who are specialized in mobile internet and data statistics. The new department of mobile finance, in combination of original financial departments and organizations, will become a unique competitive advantage for commercial banks.

In the traditional finance field, not only commercial banks but also insurance and security companies are making transformation to mobile finance. This is the same case for foreign-funded banks who are upgrading their electronic banking business. All of these intensify the horizontal competition. In 2014, for example, the Bank of East Asia launched a series of "finger banking" products-WeChat bank and cellphone bank. In the same year, the Development Bank of Singapore also started its mobile payment business, and became the first foreign-founded bank that cooperated with the Unionpay in China. If commercial banks want to stand out from the competition, they must have technological advantages and shall keep making financial innovations.

5) Government and technology

In China, governments play a crucial role in macro-regulating finance industry. Support of national policies is of great significance to the development of mobile finance. The Instructions to Promote a Healthy Development of Technological Innovations for Mobile Finance (2014), released by the People's Bank of China, claimed that mobile finance is an effective way to enrich financial service channels, to innovate financial products and service modes as well as to develop the inclusive finance [9], which provides a directional guidance for commercial banks to develop mobile finance.

It is exactly the explosion of mobile internet technologies that allows governments to see the big cake of mobile finance. Governmental support and guidance can not only drive technological innovations but also can be a 
powerful safeguard for commercial banks to build the advantages in competing mobile financial services. However, the system of laws and regulations related to mobile finance is not yet perfect. This gives a chance for many illegal internet players to defraud the revenue, which can be a big interference for commercial banks as well.

6) Opportunity

The steady and rapid economic development in China provides a supportive macro-environment for commercial banks to develop mobile finance. 2014 is the year of Chinese mobile finance, during which the mobile finance had enjoyed a rapid development that offers an opportunity for commercial banks to raise their competitive power and creates a good environment for such business.

Meanwhile, commercial banks may not achieve a good result due to the limitation of the few product categories and low yield rate. There are still many blocks on the road to the development of mobile financial services. What's more, network security problems, such as hacker and the leakage of information, are also challenges that commercial banks have to face and risks they have to avoid. Otherwise, their competitiveness in the target market will be weakened seriously.

\section{Ecological Strategies for Commercial Banks to Raising the Core Competitiveness in Developing Mobile Finance}

Characteristics of financial ecology include evolution, competition, innovation and stability. The environment of financial ecology has actions on entities of this ecology; in turn, the entities also have reaction on the environment $(\mathrm{Xu}, 2007)[10]$. In a natural ecology, each life entity cannot live without others, and they are independently living in a biological network, in which, each life has its own ecological measures for survival and development, resulting in an all-win situation (Wang, 2014) [11]. Finance has similar ecology, too. In a financial ecology, for the purpose of survival and development, each organization or individual must take a series of proper measures to adapt to environment changes, such as play its competitive advantage and cooperate with other organizations.

\subsection{Construct the Platform Ecology by Cooperation}

The concept of platform ecology comes from the natural ecology. Platform ecology is a win-win mechanism for multilateral cooperation, which, under the drive of core business, results in a virtuous cycle formed by the organic collaborations between the derivative business modules. In the era of big data, it has become a trend among those internet players to construct the platform ecology featured in flexible and dynamic value-creating system (Chen Weiru, Yu Zhuoxuan, 2013) [12].

\subsubsection{Construct the Mobile Platform by Taking Advantage of Mobile Internet Companies}

Competitive advantages of commercial banks include their good credit guarantee, various financial products, complete risk control system, and widely distributed outlets. In the mobile finance environment, however, there is a lack of competitive power in constructing mobile platform if compared to a third-party platform or communication operator. One big drawback of internet finance is that the money, which, in most cases, is not too much, cannot be deposited independently, and it still rely heavily on traditional banks. Though new credit modes being created, internet finance has to ensure smooth operations by virtue of traditional banks (Qiu, Wang and Meng, 2013) [13].

By cooperating with the third-party platforms and based on the mobile social network, commercial banks can build a bridge that connects their brands with consumers, and their operations shall be user-centered, to establish consumers' trust, participation and engagement. For commercial banks, they shall construct platform ecology of mobile finance based on core business, absorb competitive advantages from other industries, expand the scope of business, consolidate the existing profit channels and avoid risks, to acquire sustainable strengths in competition and build a bridge connecting to users. The WeChat bank launched by SPD Bank in 2013, for example, provides financial services that can be obtained via text, video, picture and voice. By virtue of WeChat, SPD Bank has established a highly widespread mobile platform, which, in turn, offers new market for the platform of WeChat.

\subsubsection{Expand the Scope of Services by Making Union with Communication Operators}

When launching cellphone payment products, commercial banks may face problems such as great investment, 
unclear profit mode and big market risks (Li and Qian, 2013) [14]. The rich customer resources and the widely distributed mobile network sites of mobile communication operators are to the benefit of expanding the scope of services effectively. Taking SPD Bank as an example, CMCC (China Mobile Communication Corporation) received $20 \%$ of the share of the bank in September 2010, by investing RMB 39.8 billion Yuan. The two parties have carried out an all-round cooperation under the Strategic Cooperation Agreement, including the business of NFC (near field communication). This is also a channel-related innovation that a user can acquire the service without changing his/her cellphone.

Because of CMCC's powerful support in communication and payment, SPD Bank is able to void its competitive weakness in platform, evade risks and make full use of its professional advantages. CMCC has also exploited a new market. Progress made by one party can improve the efficiency of the whole ecology, and their inherent competitive relation can promote innovations and reforms in other aspects, which leads to a mutual beneficial ecology.

\subsection{Construct the Industrial Chain of Mobile Finance by Innovations}

\subsubsection{Innovate Service Channels and Construct a Package of Financial Services}

In traditional finance environment, financial products are always sold independently, lacking of a close correlation, which, as a result, can not achieve the effect of mutual promotion. The emergence of mobile platforms offers an opportunity for commercial banks to integrate financial products and construct a package of financial services, which is in favor of forming a complete and smooth industrial chain. The procedure can also be shortened by using big data and cloud computing, to realize the " $\mathrm{T}+0$ " mode, which is really a "finger finance". In the mobile mall, a customer can browse all the financial products, and can consult with the bank via voice and other interactive ways, which lowers the cost of transaction, greatly reduces the information asymmetry, and enhances his/her trust on the bank and participation in finance as well.

\subsubsection{Expand the Scope of Business and Innovate Financial Products}

One the basis of core business, commercial banks shall expand the scope of their businesses. They shall also implement the allfinanz industrial chain. A customer may inquire insurance services when paying expenses of water and electricity, which is a condition for additional marketing. What's more, packages of financial services can be introduced to customers via the mix of different products. In each package, the products shall be carefully collocated to reduce risks, raise profit and offset the inherent disadvantages of a single product. The high degree of interaction of mobile platform shall be made use of to communicate with customers in time and provide personalized financial services to them. It is obvious that financial services in the industrial chain are promoted mutually and marketed jointly, which can not only cut the costs of marketing and communication, but also form a complete industrial chain, so that customers can acquire any financial service in the chain. This provides a good ecological environment for financial business.

\subsection{Construct the Biocoenosis of User Clusters}

A biocenosis is a biotic community that describes the interacting organisms living together in a specific space or environment. There are interactions between biotic individuals as well as between the individuals and the environment. The community has certain morphological structure and trophic structure, and has some specific functions (Sun, 1997) [15].

\subsubsection{Set up the User-Centered Idea and Build the User-Guided Mode}

Mobile finance is a innovative combination integration between banking and mobile technologies. It is a result of new demands. A major change of traditional finance is that financial participants are required to change their mind to establish a user-cored business mode. The mobile internet shall be used to attract new customers on one hand, and mobile APPs shall be used to make timely communication on the other hand, so as to strengthen customer stickiness, enhance their loyalty and acceptance of mobile finance platforms. Naturally, the enhancement of customer loyalty will lead to spontaneous marketing that old customers may recommend the platform to others. As a result, the self-growth of the number of users will contribute to a continuous enlarging of the biotic community. 


\subsubsection{Use the Statistics of Mobile Operations to Analyze the Clustered Customers}

By using the mobile operation platform, cloud computing and big data, commercial banks can effectively make statistics about customers' different characteristics to divide the customers into different clusters. Different financial products shall be accordingly designed for different clusters. For example, a unified marketing strategy can be made for merchants in the same material market, and the merchants can apply for micro-credit and make repay the credit via the mobile finance platform. These merchants are in an environment that they have relatively direct competition relationship with each other. The credit behavior of one merchant may be imitated by others. They all want to increase their circulating fund through micro-credits. This is a sheep-flock effect that will finally increase the total amount of financial businesses of the commercial banks.

\section{Conclusions}

Commercial banks hold a dominant position in traditional finance system; therefore, many commercial banks are not adequately driven to make strategic transformation and structure re-engineering. They rely heavily on their outlets. People feel less satisfactory about the services of commercial banks because of the cumbersome procedures as well as because limitations on small- and medium-sized financial institutions have now been gradually loosened. Consequently, commercial banks are losing their attraction.

The rapid development of mobile internet makes mobile finance an indispensable part of financial system in the future. Commercial banks are pressed to improve their competitiveness in the field of mobile finance. For many commercial banks, however, their operation modes are hidebound, with a low level of mobile information technology and single product structure. Mobile internet players and foreign-founded banks are also intensifying the competition with commercial banks in mobile financial business.

Commercial banks shall strengthen cooperation with the third-party platforms and operators. Only in this way can they innovate their financial products, enlarge the service scope, build up the demand-oriented business mode, and construct the mobile financial ecology that covers the banking industry, the banks and customers. Mobile finance is an important platform for developing inclusive finance. Commercial banks can seek support from government policies, including tax preferences, shall be alert to problems such as the leakage of information and hacker attack in the internet environment, and shall put emphasis on safety construction for mobile financial business.

\section{References}

[1] Xie, P. (2014) Report of Internet Finance 2014: A Way to Rational Prosperity. http://www.boaoforum.org/2014nhtpbd/12745.jhtml

[2] Li, D.R. (2015) Mobile Finance to Enter into a Faster Development Period. People's Daily, 7.

[3] Cao, F.Q. (2014) Mobile Finance to Open a New Financial Era. http://www.drcnet.com.cn/eDRCnet.common.web/docview.aspx?DocID=3758642\&leafid=15140\&chnid=281

[4] Hu, S.L. (2014) Mobile Internet Finance Market Is Developing in Innovations. Renmin Youdian Bao.

[5] GSMA (2014) Mobile Financial Services State of the Industry Report.

[6] Porter, M.E. (2002) The Competitive Advantage of Nations. Translated by Li Mingxuan and Qiu Rumei, Huaxia Publishing House, Beijing.

[7] The 2014 Annual Report of Shanghai Pudong Development Bank. http://www.spdb.com.cn/chpage/c438/doclist.aspx?COLLCC $=2237664089 \&$

[8] Sheng, X.L. and Jiang, M.S. (2014) Financial Service Is Everywhere. The Time Weekly.

[9] People's Bank of China Instructions to Promote a Healthy Development of Technological Innovations for Mobile Finance. www.chinairn.com/news/20150204/17281017.shtml, 2015-2-4

[10] Xu, N.J. (2007) On Finance Ecology--A Challenge to Traditional Financing Ideas. China Finance Publishing House, Beijing.

[11] Wang, Q. (2014) Study on Platform Ecology and Finance Ecology of Internet Companies—Based on the Perspective of Shared Values. The Journal of Finance.

[12] Chen, W.R. and Yu, Z.X. (2013) Platform Strategy: A Revolution of Commercial Mode Sweeping the World. China CITIC Press, Beijing.

[13] Qiu, Y.W., Wang, L.F. and Meng, Q.J. (2013) Study on Ecological Strategies for Commercial Banks Responding to 
Challenges of Mobile Internet. Manager' Journal.

[14] Li, L. and Qian, F. (2013) Mobile Banking - Creating New Financial Service Model in the Age of Mobile Internet. Tsinghua University Press, Beijing.

[15] Sun, R.Y. (1997) General Ecology. Higher Education Press, Beijing. 